\title{
Intraoperative Blood Product Administration
}

National Cancer Institute

\section{Source}

National Cancer Institute. Intraoperative Blood Product Administration. NCI Thesaurus.

Code C159284.

A header for a form section about intraoperative blood product administration. 